\title{
Examination of different grain hardness varieties of the grinding technology properties of wheat
}

\author{
BALÁZS P. SZABÓ - ZOLTÁN MAGYAR - ANTAL VÉHA \\ University of Szeged, Faculty of Engineering, Szeged, Hungary \\ szpb@mk.u-szeged.hu
}

\begin{abstract}
Summary
In the mill industry, the purpose of the grinding technology is to separate wheat endospermium and shell and to recover grists. The most important and the highest energy requirement operation is shredding. Flour quantity and quality produced from wheat depends on the variety of wheat that will be shredded, the type of grinding equipment and the condition used before the grinding. For this reason, during my experiments, I ground two grain structured varieties of wheat in laboratory conditions using a disk grinder, stone grinder and roll grinder in air-dry and conditioned states. We measured the equipment's performance and the produced grist's particle size distribution, followed by the calculation of the energy requirements of the grinders. In the grinding experiments we compared the ash contents of the different particle sized grist's fractions to map the wheat's particular properties.
\end{abstract}

Keywords: Hungarian wheat varieties, disc grinder, roll grinder, stone grinding

\section{Introduction}

Nowadays wheat is one of the most common grain plants. It plays an indispensable role in our everyday nutrition worldwide. Its processing extends to the animal feed as well, but its main role is in the mill industry, as the basic raw material.

The grading based of grain hardness is extremely important for milling and for other industries as well that use wheat flour. In grinding technology the degree of grain hardness of the wheat is proportional to the energy used for grinding, since the grinding of harder grain requires far more energy than soft wheat. In addition the grain hardness rate specifies the conditioning parameters, the flour particle size, the density, the starch damage rate and through this the flour water absorption ability and the flour yield rate. The industries processing various flours select raw materials based on grain hardness and protein content. The hard endosperm structure is closely related to the high yield rate of flour, furthermore the proportion of yields is higher of valuable fractions, the water absorption capacity of the flour is higher and the quality of the bread is also better (Mousia, 2004; Bottega, 2009; Ranieri, 2011). 
In the mill industry our objective of grinding is to separate the wheat's endospermium and shell part, and to recover grists out of it. The most important and the highest energy-consuming operation is grinding. The flour's quantity and quality produced from wheat depends on: the variety of wheat that will be ground, the type of grinding equipment and the conditioning used before the grinding. This is the reason that during my experiments we ground two grain structured varieties of wheat in laboratory conditions with a disk grinder, a stone grinder and a roll grinder in air-dry and conditioned circumstances. We measured the equipment's performance from which we calculated the produced grist's particle size distribution and the energy requirement of each grinder. In the grinding experiments we compared the ash contents of the different particle sized grist's fractions to map the wheat's particular properties.

\section{Material and methods}

Our experimental materials were GK Békés and GK Fény. The GK Békés wheat type was published in 2007 , because of the increasing demands of the high quality wheats. Its adaptability is excellent, practically it can be grown in any areas of the country. Among its nutritional features, the stable high quality and high quality wet protein content is outstanding.

The GK Fény's adaptability to extreme weather conditions and different types of soils is very nice. Its resistance to general diseases is excellent, as a result it's suitable for bio-cultivational bread baking. Its quality is general and standard grade. Its bakery industry classification is B1-A2. The GK Fény can be grown safely in any area of the country.

As we wrote we examined the wheat samples in two different moisture conditions: first $11 \%$ "air-dry" and secondly on $15.5 \%$ "conditioned".

During the experiments we used disk, stone and roll grinder equipment. As disk grinder we used a Perten 3303 laboratory equipment.

The grinding takes place between a stationary and a rotating disk. In this equipment the fineness of the milling can be controlled by adjusting the space between the disks. There are 6 different types on its scale. Our measurement was performed at the lowest gap, "0" position. The disk grinder's most important technical parameters: motor power $180 \mathrm{~W}$, dial speed 28001 per min and the dial's diameter is $75 \mathrm{~mm}$. The stone grinder was a custom-made equipment and was designed primarily for experimental purposes. The grinding is made by grinding stones located on a horizontal axis. One stone is stationary, the second one is rotating. The stone grinder's most important technical parameters: motor power $1500 \mathrm{~W}$, dial speed 7351 per min, dial's diameter is $250 \mathrm{~mm}$. The roll grinder was a QC 109 type laboratory mill. In the device the wheat is 
moving along rolls, that rotate different speed. The size between the rolls is factory-set, and cannot be changed, thus ensuring the stability of the parameters during the experiment. The roll grinder's most important technical parameters: motor power $480 \mathrm{~W}$; rolls speed 9801 per min; peripheral speed is $3.6 \mathrm{~m}$ per s; the rolls' diameter $70 \mathrm{~mm}$; the referral of the rolls is 2.4 .

The power of the two-phase disk grinder was measured using Voltcraft Energy Logger 3500 type electric power meter. The power of the three-phase stone and roll grinder was measured by Fluke 435 Series II Power Quality and Energy Analyzer. During the measurements the machines were worked empty for the first minute to determine the power of empty run, and then the wheat samples were measured. During the empty and normal runs using the Voltcraft device we read and recorded every 10 seconds the power that was written on the equipment's screen, while the Fluke device saved automatically the data every 10 seconds, which data could be used and edited on the computer later. During the grinding we measured the mass of the grist at least three times with stopwatch to determine the mass flow.

One of the most common method of classifying the powders and grists on particle size is the sieve analysis. On each sieve only those fractions can pass through, which are the same size or smaller size compared to the sieve's holes. During this procedure we used upwardly rising sieves, which were stacked on each other. The wheat materials that are tested is poured onto the top sieve, then the sieve column is subjected to a regular shake movement. At the end of the test we weighed the mass of the materials remained on each sieve. Thus the percentage of all materials can be determined. Also the wheat material can be broken down into average particle size fractions. The sieve analysis was carried out using the Fritsch Analisette 3 type vibration sieve. The series of the sieves consisted of 12 , and the dimensions were: $63,100,200,250,300$, $400,500,600,800,1250,1800$ and $2500 \mu \mathrm{m}$. To prevent the clogging of the sieves we used four $20 \mathrm{~mm}$ diameter sized rubber balls. We weighed the sieves in empty state. Then we set up the sieve column, and added the $100 \mathrm{~g}$ grist, closed the cover, and launched the device. We set $1.5 \mathrm{~mm}$ amplitude, and 10 minutes. After the procedure we weighed the sieves and measured the residues' weight and calculated the percentage of fractions. After the sieve analysis we collected every fractions separately.

The moisture content was measured according to MSZ 6369-4 1987 in drying oven at $130{ }^{\circ} \mathrm{C}$ and for two hours from ash content. The samples were weighed in porcelain crucibles, and after incineration it was in oven at $550{ }^{\circ} \mathrm{C}$ for 6 hours. 


\section{Results and discussion}

In the following Table 1 the measurements of the sample grinding can be seen, that were calculated from the main parameters. Since we could not ensure the dosing stability of the mass flow during the measurement, we compared the energy values to the measured mass flows. The specific energy demand of grinding in $\mathrm{kWh}$ per $\mathrm{t}$ is shown in Figure 1.

Table 1. The characteristics of grindings

\begin{tabular}{|c|c|c|c|c|c|c|c|}
\hline Type & $\begin{array}{c}\text { Moisture } \\
\text { content. } \\
(\%)\end{array}$ & Grinder & $\begin{array}{c}\text { Power in } \\
\text { empty } \\
\text { state } \\
(\mathrm{W})\end{array}$ & $\begin{array}{c}\text { Grinding } \\
\text { power } \\
\text { (W) }\end{array}$ & $\begin{array}{c}\text { Used } \\
\text { power } \\
(W)\end{array}$ & $\begin{array}{c}\text { Mass flow } \\
\left(\mathrm{g} \mathrm{s}^{-1}\right)\end{array}$ & $\begin{array}{c}\text { Specific } \\
\text { energy } \\
\text { demand } \\
\left(\mathrm{kWh} \mathrm{t}^{-1}\right)\end{array}$ \\
\hline GK Békés & 11 & disk & 100.8 & 316.9 & 216.1 & 3.8 & 16.0 \\
\hline GK Békés & 15.5 & disk & 101.1 & 329.4 & 228.3 & 3.3 & 19.5 \\
\hline GK Fény & 11 & disk & 101.6 & 297.9 & 196.3 & 3.8 & 14.4 \\
\hline GK Fény & 15.5 & disk & 102.1 & 351.5 & 249.4 & 3.5 & 19.9 \\
\hline GK Békés & 11 & stone & 370.0 & 1195.0 & 825.0 & 14.9 & 15.4 \\
\hline GK Békés & 15.5 & stone & 380.0 & 756.0 & 376.0 & 5.7 & 18.3 \\
\hline GK Fény & 11 & stone & 375.0 & 822.0 & 447.0 & 11.1 & 11.2 \\
\hline GK Fény & 15.5 & stone & 380.0 & 665.0 & 285.0 & 4.4 & 17.9 \\
\hline GK Békés & 11 & roll & 175.0 & 288.0 & 113.0 & 3.2 & 9.9 \\
\hline GK Békés & 15.5 & roll & 170.0 & 285.0 & 115.0 & 2.8 & 11.4 \\
\hline GK Fény & 11 & roll & 170.0 & 241.0 & 71.0 & 2.8 & 7.0 \\
\hline GK Fény & 15.5 & roll & 175.0 & 273.0 & 98.0 & 3.1 & 8.9 \\
\hline
\end{tabular}

Figure 1. Specific energy demand of grinding

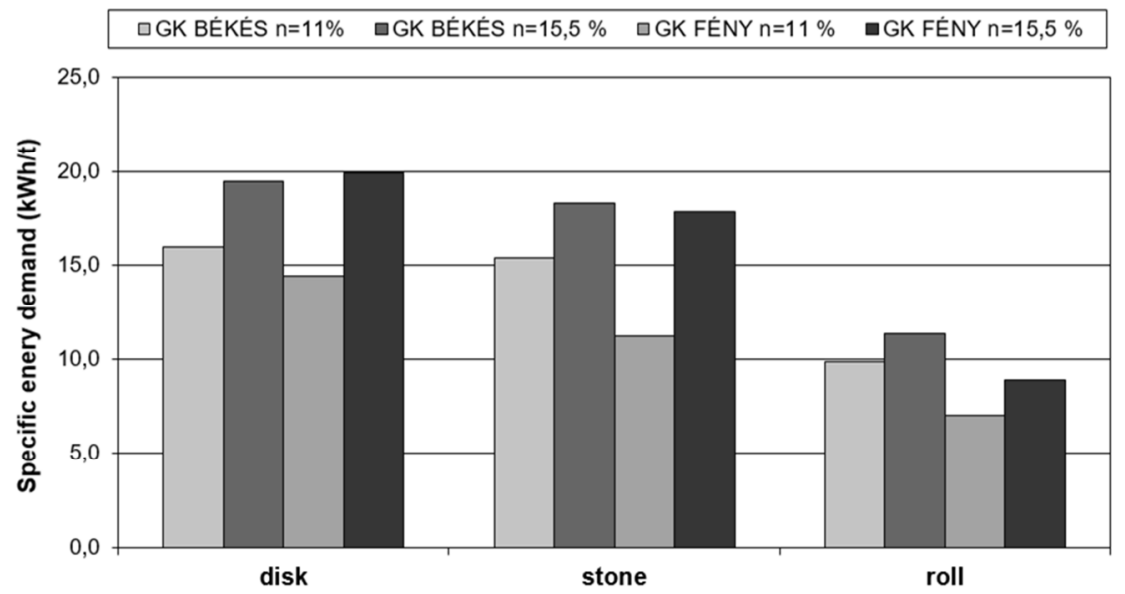

From the first chart it can be read at air-dry state (11\%) from the two wheat types the GK Békés' specific energy demand of grinding is higher 
compared to GK Fény, but due to conditioning (15.5\%), this difference can only be felt in roll grinding. The roll grinder has the smallest specific energy demand, the disk grinder has the largest, although there is no significant difference between the disk and the stone grinder. The conditioning in each case increased significantly the energy demand, but this amount was the smallest in roll grinding.

The results we got from the analysis' fraction volumes for describing the particle distribution we made histograms, in such a way that we divided the individual sieve residues by the following sieves' size differences. The relative frequency values thus we obtained were depicted as a function of the particle size. Three factors' (wheat type, grinding device, conditioning) effects can be seen on the following three charts (Figure 2-4).

During the sieve analysis we could observe that the hard type GK Békés has definite mode, while the soft type GK Fény has two mode distribution. GK Fény has produced a much larger quantity flour granule in the range of 100 to $200 \mu \mathrm{m}$, while GK Békés has produced the most grains fell within range of $300-400 \mu \mathrm{m}$. In addition to this, it can be concluded that in the case of GK Fény has a more spacious distribution.

Figure 2. GK Békés and GK Fény wheat types' grists' particle size distribution in conditioned state with roll grinder

GK FÉNY $n=15,5 \%$ roll grinding

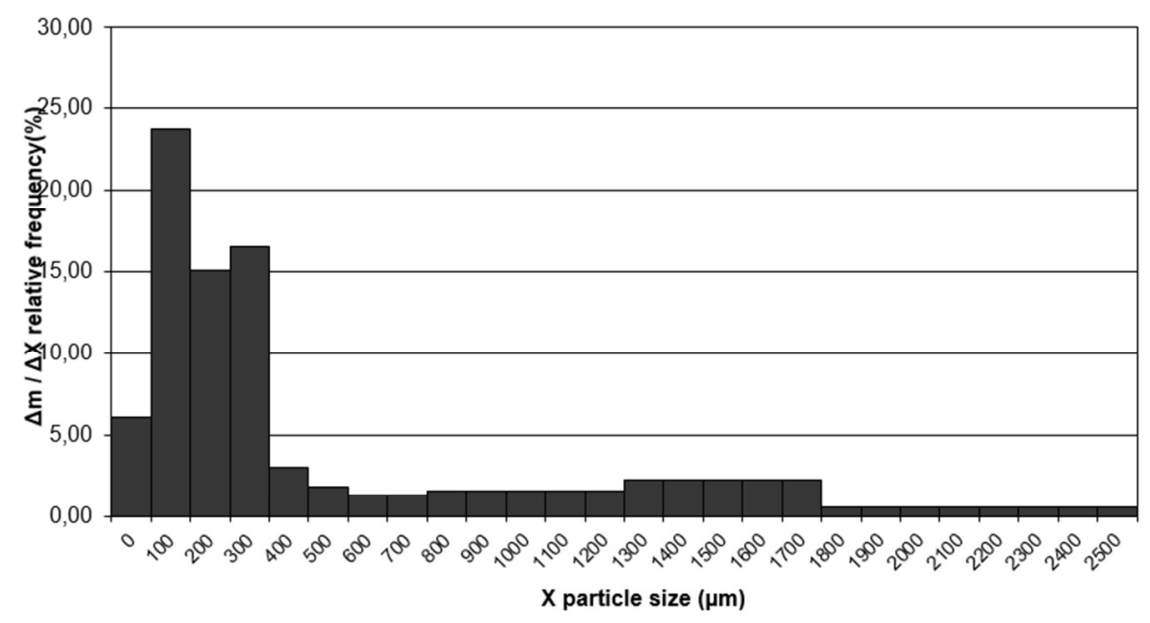


GK BÉKÉS $n=15,5 \%$ roll grinding

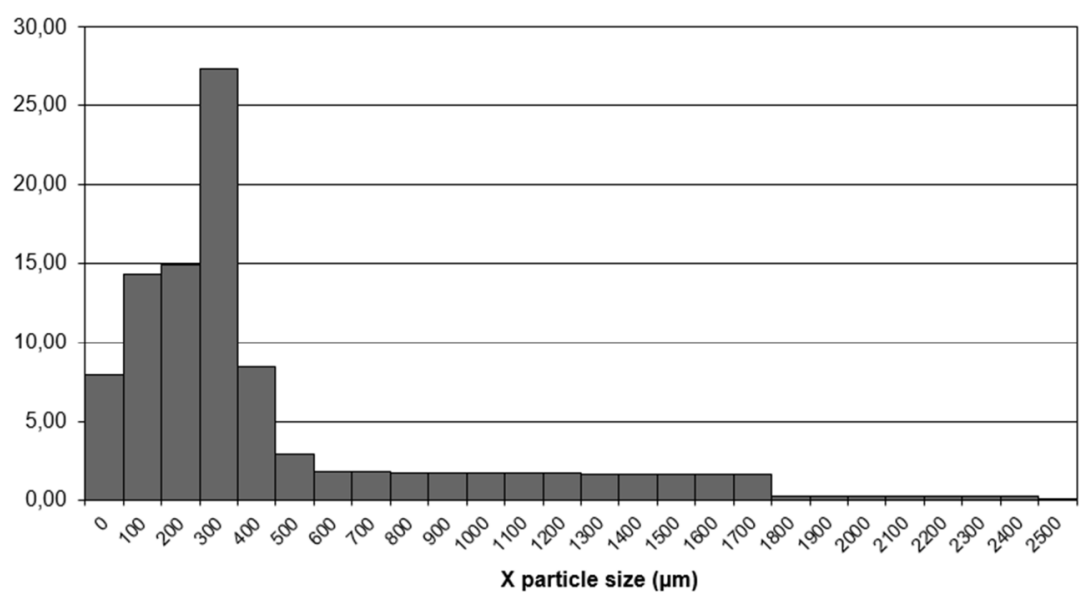

As regards the particle size distribution of the grist of the same wheat sample from the three grinders, on the Figure 3 that can be concluded that there is no difference in the mode particle size, but in the case of roll grinder the spacing of the distribution is significantly different, much larger shell particles were produced than the other two grinders. This shows the separating characteristics of the roll grinder, the core fragments into smaller pieces, meanwhile the shell fragments in larger pieces.

The conditioning effect on GK Békés can be seen on Figure 4. It can be observed that the mode of the particle size did not change after conditioning on $15.5 \%$ moisture content, but less smaller grain was obtained and the size range of large shell grains increased. This proves that the separating characteristic is increasing after conditioning.

In addition to the particle size distribution we also wanted to know how much proportion of wheat shells and cores were part of the grain size ranges, as the grinding technology main aim is to separate them.

Therefore, we determined the fractions' ash content (Table 2).

On the Figure 5 it can be seen the wheat types' grists' ash contents on $15.5 \%$ moisture content examining roll grinder. The soft wheat GK Fény's fractions have lower ash contents, but we can find grist on larger size ranges as well. This phenomenon refers to the soft type's flour-like fragmenting, and the larger particles are flattened while they are grinded, and more core parts can attach to them comparing to GK Békés. 
Figure 3. The disk, stone and roll grinding's grists' particle size distribution on $15.5 \%$ moisture content examining GK Békés type

GK BÉKÉS n=15,5\% disk grinder

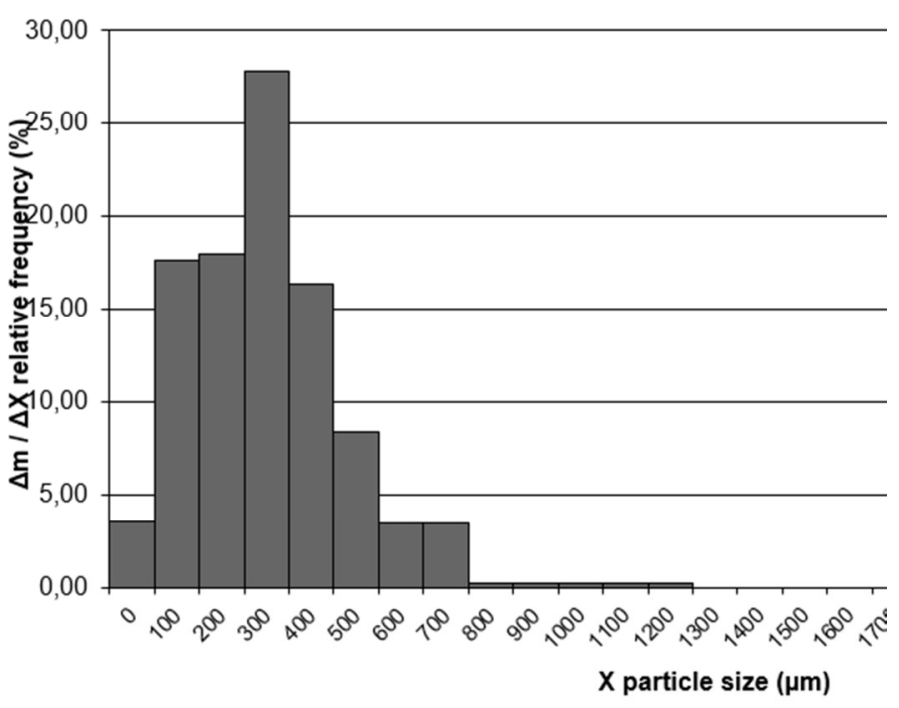

GK BÉKÉS n=15,5\% stone grinder

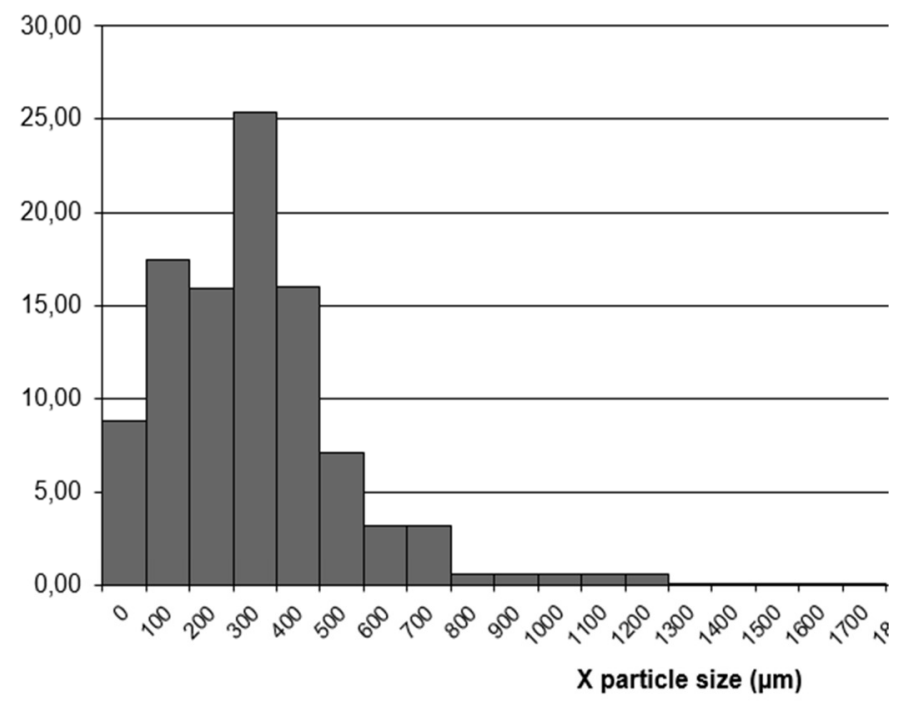


GK BÉKÉS $n=15,5 \%$ roll grinding

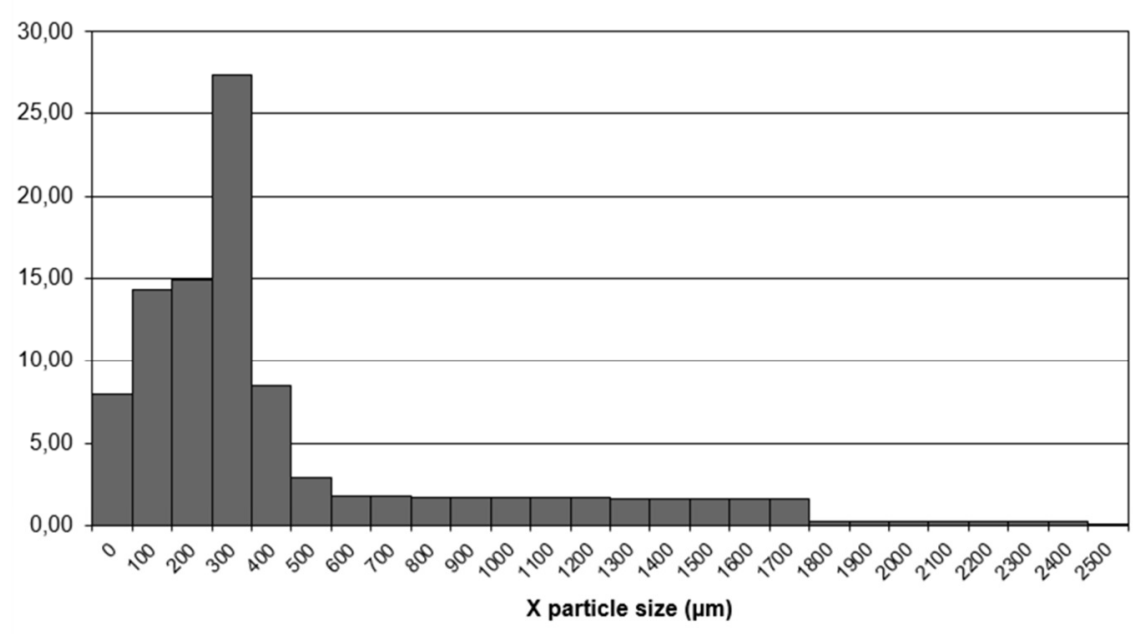

Figure 4. Particle size distribution at $11 \%$ and $15.5 \%$ moisture content produced by roll grinder on GK Békés

\section{GK BÉKÉS $n=11 \%$ roll grinding}

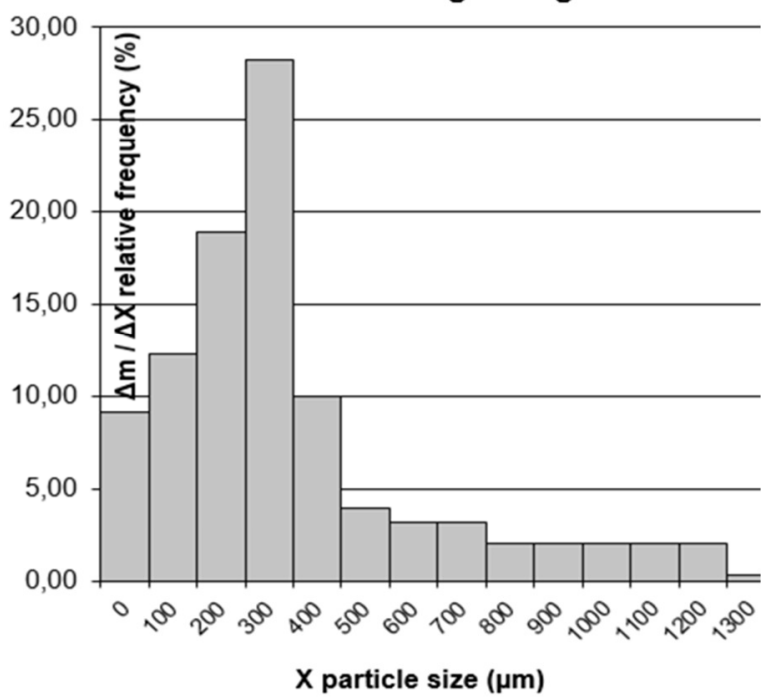


GK BÉKÉS $n=15,5 \%$ roll grinding

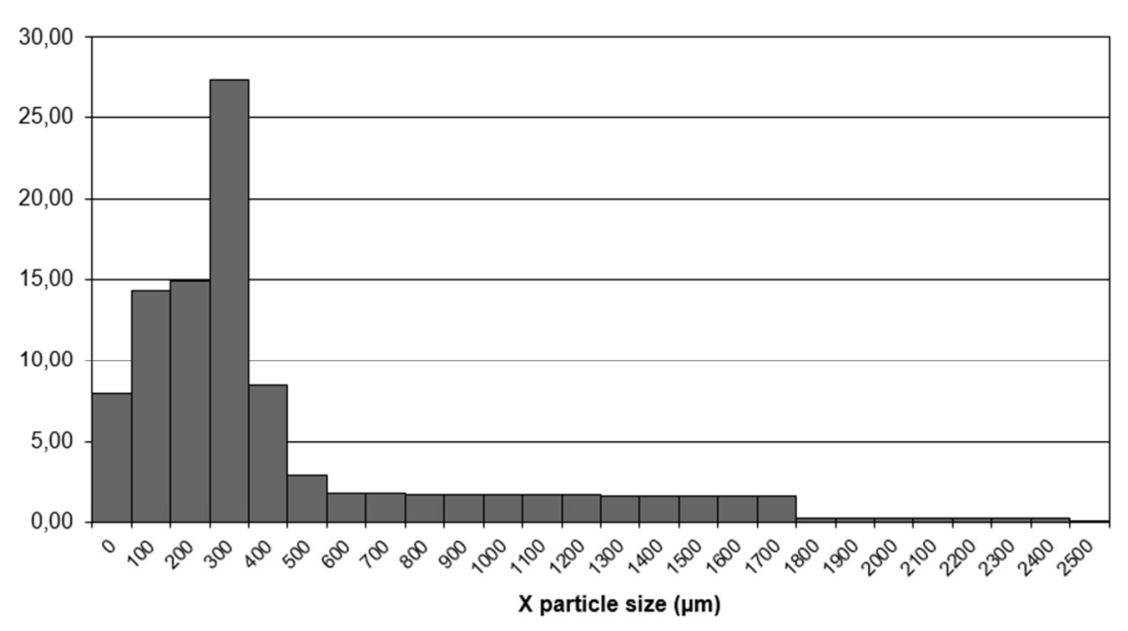

Figure 5. Fractions' ash content examining $15.5 \%$ moisture content, and roll grinding

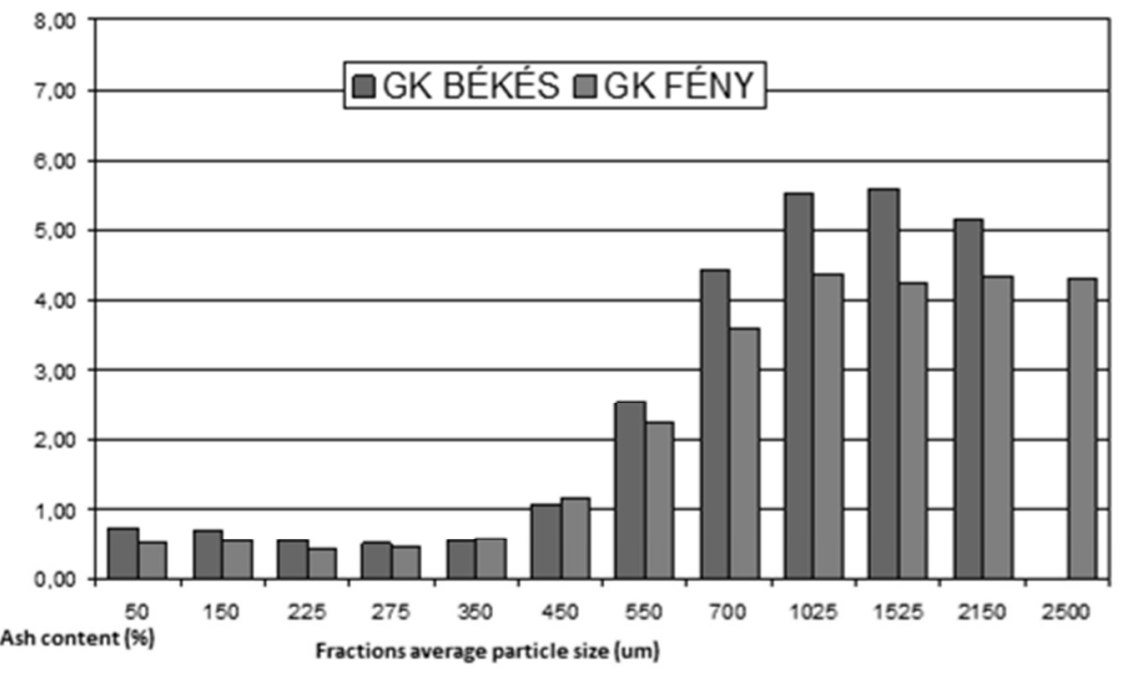


Table 2. Sieve fractions' ash content

\begin{tabular}{|c|c|c|c|}
\hline Type & Moisture content (\%) & Grinding & Ash content $(\%)$ \\
\hline \multirow{9}{*}{ GK Békés } & \multirow{9}{*}{15.5} & \multirow{9}{*}{ stone } & 1.64 \\
\hline & & & 1.65 \\
\hline & & & 1.19 \\
\hline & & & 1.06 \\
\hline & & & 1.09 \\
\hline & & & 1.50 \\
\hline & & & 2.63 \\
\hline & & & 5.25 \\
\hline & & & 6.75 \\
\hline \multirow{12}{*}{ GK Fény } & \multirow{12}{*}{15.5} & \multirow{12}{*}{ roll } & 0.53 \\
\hline & & & 0.57 \\
\hline & & & 0.44 \\
\hline & & & 0.46 \\
\hline & & & 0.59 \\
\hline & & & 1.17 \\
\hline & & & 2.23 \\
\hline & & & 3.60 \\
\hline & & & 4.36 \\
\hline & & & 4.25 \\
\hline & & & 4.33 \\
\hline & & & 4.30 \\
\hline \multirow{11}{*}{ GK Békés } & \multirow{11}{*}{15.5} & \multirow{11}{*}{ roll } & 0.74 \\
\hline & & & 0.72 \\
\hline & & & 0.57 \\
\hline & & & 0.52 \\
\hline & & & 0.55 \\
\hline & & & 1.09 \\
\hline & & & 2.54 \\
\hline & & & 4.41 \\
\hline & & & 5.51 \\
\hline & & & 5.60 \\
\hline & & & 5.16 \\
\hline \multirow{9}{*}{ GK Békés } & \multirow{9}{*}{15.5} & \multirow{9}{*}{ disk } & 1.61 \\
\hline & & & 1.66 \\
\hline & & & 1.22 \\
\hline & & & 1.15 \\
\hline & & & 1.18 \\
\hline & & & 1.75 \\
\hline & & & 2.77 \\
\hline & & & 4.93 \\
\hline & & & 7.08 \\
\hline \multirow{10}{*}{ GK Békés } & \multirow{10}{*}{11} & \multirow{10}{*}{ roll } & 1.14 \\
\hline & & & 0.73 \\
\hline & & & 0.69 \\
\hline & & & 0.64 \\
\hline & & & 0.92 \\
\hline & & & 1.88 \\
\hline & & & 3.26 \\
\hline & & & 4.89 \\
\hline & & & 5.55 \\
\hline & & & 5.59 \\
\hline
\end{tabular}


The ash content of the fractions produced by each grinders is shown in Figure 6. There is no significant difference between the disk and stone grinder's ash content. The roll grinder's separating characteristic shows up here as well. The flours that were produced are much lighter and rich in core parts. The parts that contain high ash content shell parts are bigger, but more core parts are attaching to them, therefore they have a lower ash content.

The conditioning effect can be seen in the Figure 7 . The wetter wheat fractions have a lower ash content.

Figure 6. Fraction's ash content examining GK Békés in conditioned state (15.5\%) all three grinders

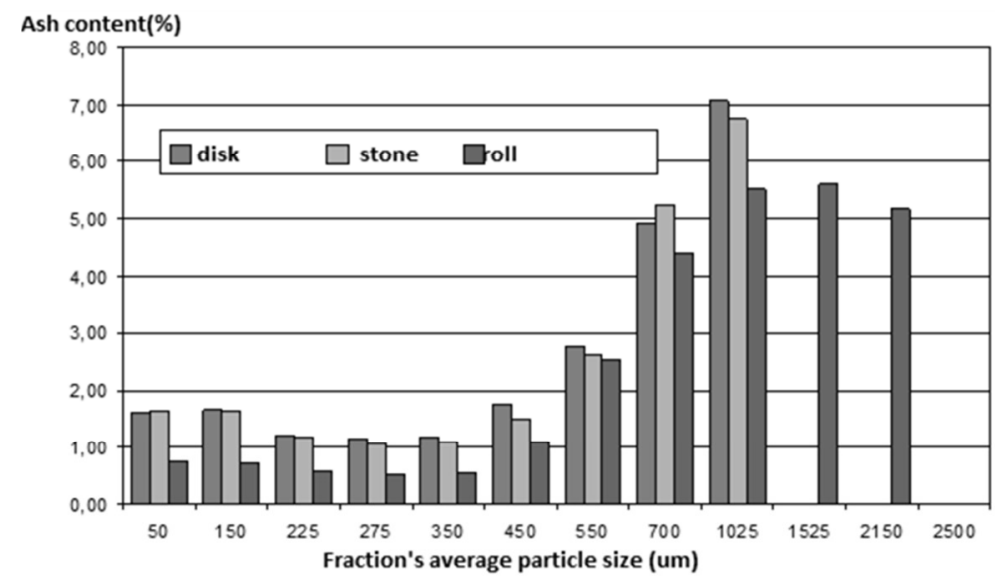

Figure 7. Fraction's ash content in GK Békés produced by roll grinder

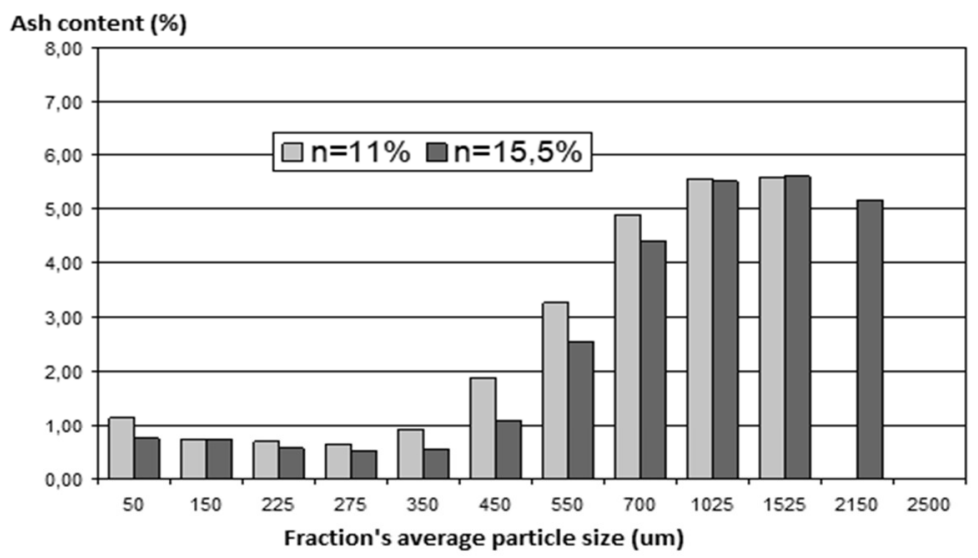




\section{Conclusions}

The ash content differences can be seen clearly in the fractions on Figure 8-10. The GK Fény's fractions are lighter than the GK Békés' (Figure 8).

Examining the GK Békés with roll grinder it is clear that after the conditioning the flours were whiter and the range of size was increased, so the separating character as well (Figure 9). The separating characteristic in the roll grinder comes out on the Figure 10 compared to stone and disk grinders. The size of the range increased and the grains are lighter in smaller range.

Figure 8. First line GK Fény n=15.5\%, roll grinder; second line GK Békés n=15.5\%, roll grinder

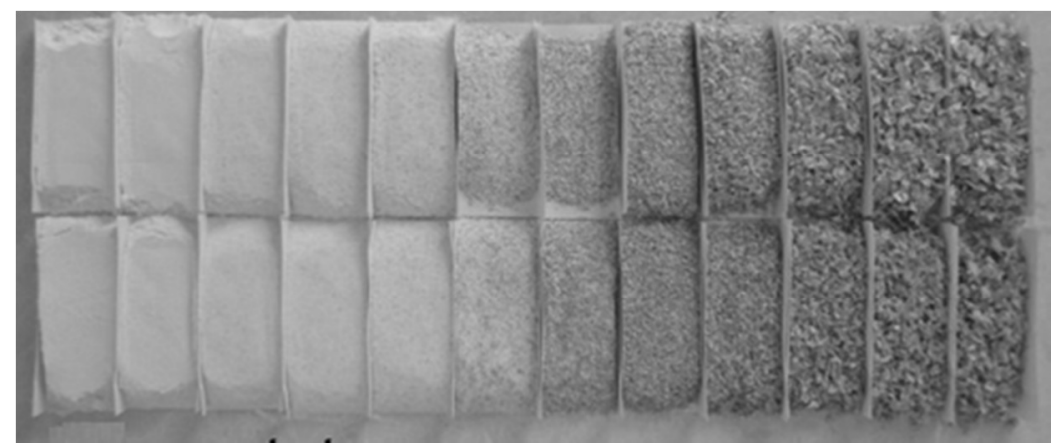

Figure 9. First line GK Békés n=11\%, roll grinder; second line GK Békés n=15.5\%, roll grinder

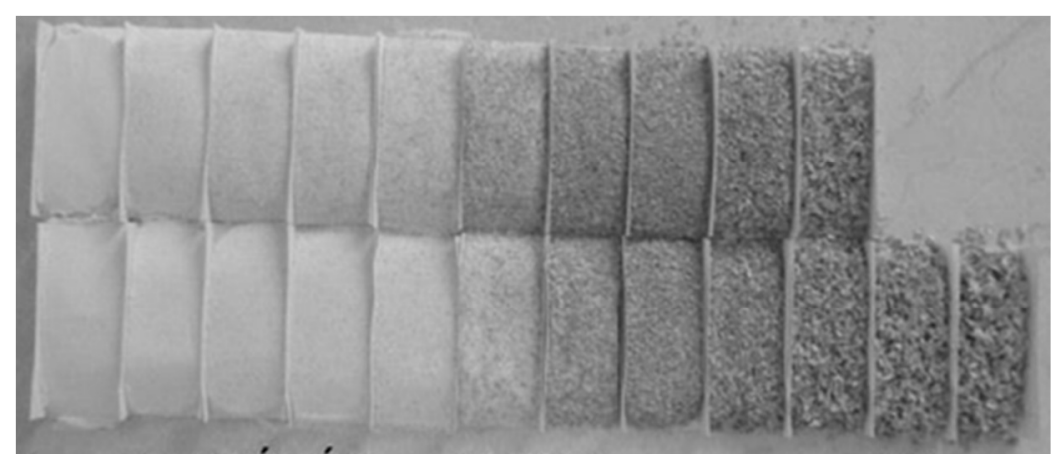


Figure 10. GK Békés $n=15.5 \%$ stone, disk and roll grinder

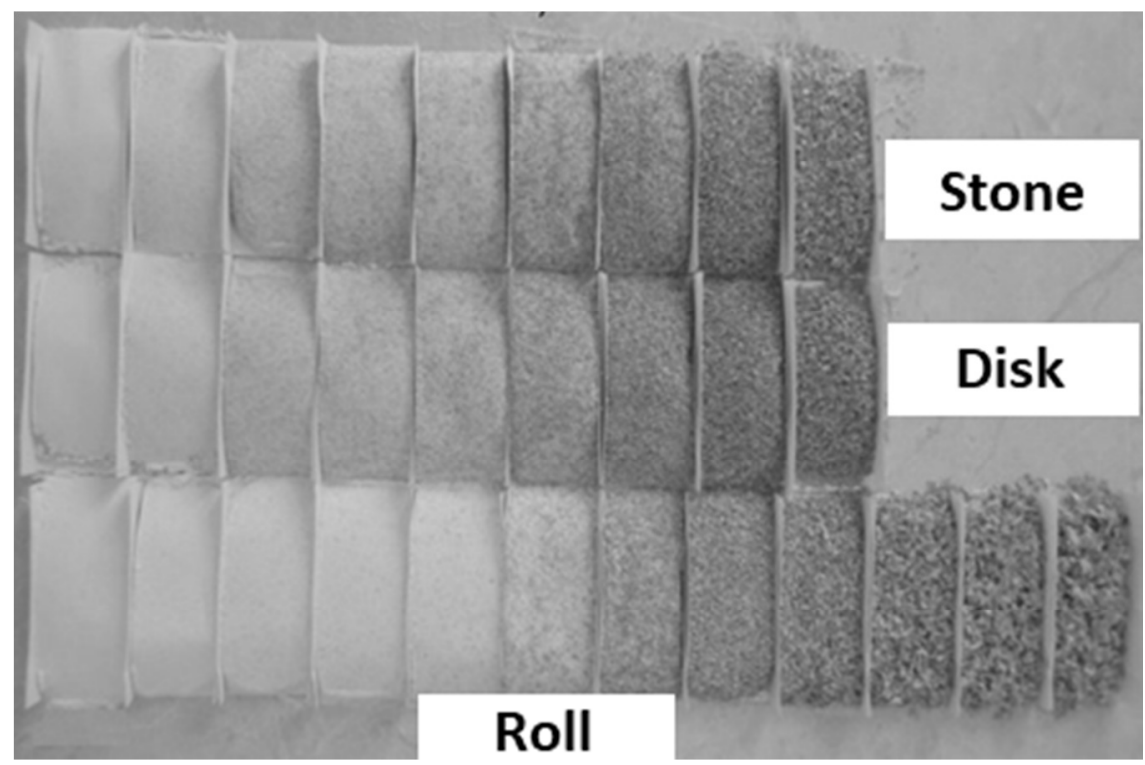

\section{References}

Bottega, G.-Cecchini, C.-D'Egidio, M. G.-Marti, A.-Pagani, M. A. (2009): Debranning process to improve Quality and safety of wheat and wheat products - Tecnica Molitoria International - Yearly issue 67-68. http://www.openfields.it/doc/110919-openfields.pdf

Mousia, Z.-Edherley, S.-Pandiella, S. S.-Webb, C. (2004): Effect of wheat pearling on flour quality. Food Research International. 37: 449-459.

Ranieri, R. (2011): Wheat debranning: industrial applications on durum wheat. Open Fields srl. Parma. Italy. September 13 $13^{\text {th }} 2011.6^{\text {th }}$ Annual IAOM Eurasia District Florence. Italy. 